DOI: $10.2478 / \mathrm{clb}-2019-0003$

\title{
O CARTOGRAFIERE A SPAȚIULUI RURAL ÎN ROMANUL ROMÂNESC INTERBELIC
}

\begin{abstract}
The purpose of this study is to demonstrate that using Romanian Interwar Novel we could draw a cartography of rural space. Even in the modern writers fiction we will analyse many rural spaces that we could find in some of the novels. Also, in another novels we found out that the rural space plays an important role in the construction of the narrative plot.
\end{abstract}

KeyWords: map, rural space, Camil Petrescu, fiction, cartography, narrative plot

Romanul românesc interbelic a produs, în istoria literară românească, o formulă literară încetățenită în conștiința culturală. Este vorba de coagularea romanului românesc modern și, implicit, dacă ar fi să ne raportăm la bine cunoscuta teorie a lui Lovinescu, a introducerii spațiului urban în cel literar. Când spunem acest lucru, ne referim la faptul că modernitatea a echivalat, pentru o bună perioadă, cu citadinismul, fiind legată direct de modul în care clasele sociale se raportează la oraș, drept o formă de evoluție dinspre rural. De multe ori analizat depreciativ, spațiul rural a impus o realitatea de secolul XIX, prelungindu-se spre jumătatea secolului al XX-lea. În literatura contemporană, spațiul rural este perceput fie ca loc de refugiu, fie ca un spațiu (culmea!) alienant, la care naratorul sau personajul se raportează ca la un tărâm fantastic, rupt de realitatea cotidiană.

Spațiul rural în romanul românesc interbelic implică, în afara sensurilor primare de analiză a relațiilor dintre personaje, un principiu ordonator, acela de a folosi inserții elocvente despre așezarea geografică, despre comunitate, despre spațiul exterior/cel interior, modul în care se articulează mentalitatea în funcție de organizarea spațială etc. Nu ne propunem să analizăm resorturile pe care le-a avut la bază deplasarea populației de la sat la oraș, ci, vom avea în vedere tangențial un soi de emigrare, din dorința de schimbare. Or, tocmai această

\section{6}


sciendo

trecere de la rural la urban, de la sat la oraș și sentimentele contradictorii pe care le-au generat acest demers social se regăsesc la majoritatea romanelor din perioada interbelică.

Se regăsesc mai multe tipuri de spații care aparțin umbrelei extinse a ruralului, precum cârciuma. De exemplu, în Răscoala: „În Amara, la cârciumă, obișnuiau să se strângă oamenii, în sărbători, de prin toate satele ce au ținut odinioară de domeniile Iuga. A rămas așa din bătrâni, când aci veneau toți cu toate durerile, și cei din Lespezi, și cei din Vaideei și Bârlogu, întocmai ca și cei de la Gliganu sau de la Babaroaga, fără a mai pomeni pe cei din Ruginoasa, care erau în Amara ca acasă”. (105) ori Grigore observa cu atenţie ș i satele, ș i câmpurile, parc-ar fi căutat să ghicească o taină. Sub bolta mohorâtă, pământul negru se zgribulea pătat cu dese ochiuri de apă tulbure, iar prin sate țăranii, ca duminica, mai pe la cârciumă, mai pe la câte o casă, se sfătuiau ca și altă dată. (290) Tot la cârciumă și ulterior la horă o vede/întâlnește Puiu Faranga pe Mădălina, în satul Vărzari, în drum spre Mănești: „Avea planul ceva romantic și atrăgător: să cutreieri satele căutând o țărăncuţă nostimă pentru boier ca s-o ia de nevastă”(173) În același timp, spațiul rural este departe de a fi văzut idealizat, cum se întâmpla la Sadoveanu, căci Rebreanu observă cu ascuțime: „Când ne văzu mama Mădălinei intrând în ogradă, să se topească de zăpăceală. Ne pofti totuși, cu ajutorul hangiului, în casă. O murdărie și o sărăcie cum numai la noi la țară se găsește” (189, Ciuleandra).

În Răscoala, Rebreanu păstrează o dualitate a planurilor urban/rural. Satul este văzut ca centru de iradiere a răscoalei, dar sunt aduse în discuție și sentimentele dezrădăcinării, pe care țăranii le trăiau, în cazul ruperii de spațiul rural. La autorul realist este surprinsă cel mai bine incertitudinea socială și pendularea între rural și urban, cu toate consecințele care apar: „Feciorul a ajuns grefier la București, două fete le-a măritat după preoți, iar pe cea mai mică, pe Florica, cu Pavel Tunsu, în sat. A crezut că Florica cu Pavel îi vor fi toiagul bătrâneților și i-a luat în casa ei, să trăiască toți împreună. O chema feciorul mereu la București, la dânsul, ca să nu se mai trudească și să fie tihnită după atâta amar de muncă. N-a vrut să se înstrăineze de pe locurile unde s-a născut și a îmbătrânit. Împlinise șaizeci de ani, dar se simțea încă zdravănă, măcar că i se cocârjise puț in spinarea”.(127) sau, ,În Amara, în jurul cârciumii lui Busuioc, era mai multă lume ca de obicei. Ichim spuse că s-au adunat oamenii și din celelalte sate din pricina călăreților care au trecut de dimineață cu poruncile lui Vodă”. Din nou, spațiul de răscruce este 
Sciendo

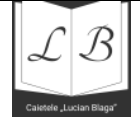

cârciuma, o zonă a dialogului între personaje, un loc în care sunt vehiculate informațiile și sunt aflate noutățile.

Corespondentul cârciumii din proza lui Sadoveanu este hanul, regăsit ca un spațiu între rural și urban. Hanurile Ancuței, al lui Gorașcu Haramin, al lui Moș Precu ori alte locuri de taifas reprezintă un moment de concentrare a spațiului și timpului, un sens al geografiei rurale. Trecând peste semnificațiile bine cunoscute din Hanu Ancuței, regăsim în Oameni din lună (1929), faptul că Sadoveanu recurge la același procedeu pe care îl folosește în majoritatea romanelor, în care spațiul rural este văzut drept un punct de tip ab origo, sursa primară prin care trecerea spre urban se face ca o diluarea a substanței. Eudoxiu: „Tatăl meu mi-a povestit pribegia lui și mi-a vorbit și de acele zile din copilărie pe care le-a petrecut în munte, în mijlocul unor oameni tari. Îi rămăsese o amintire plină de poezie. Turmele părăsind costișele și pădurile

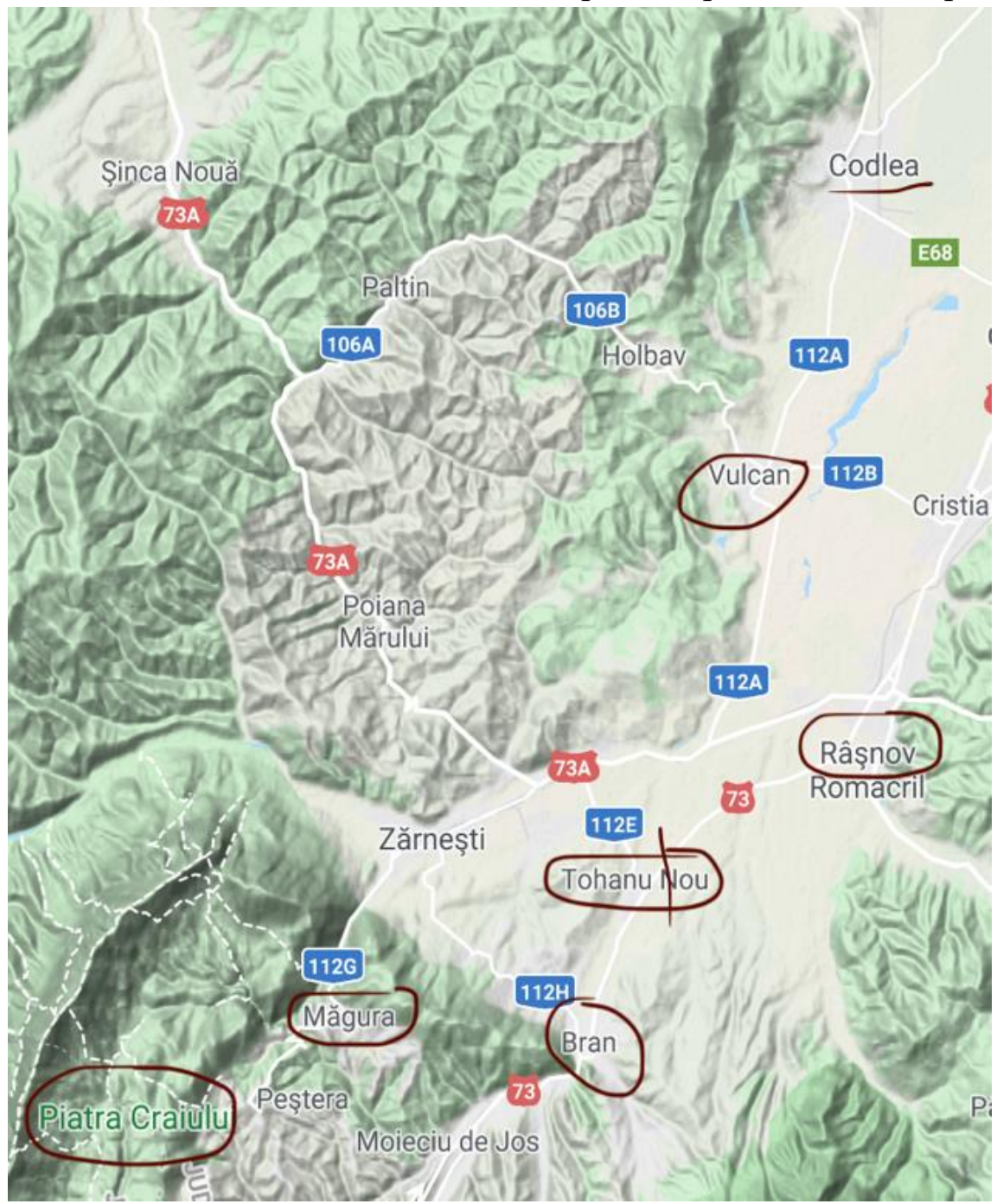
de brazi și coborând în câmpie, toamna, la iernatic. Flăcăi cu toiege nalte, câni cu ragilă la gât, și oi multe pe miriști și imașuri... Drumuri lungi, într-o căruță căptușită cu sarici; popasuri grave și iarăși porniri, ca întrun exod misterios" (309). Spațiul rural îndeplinește aici o funcție de opoziţie față de urban, față de citadinismul perceput drept o zonă interzisă, degradată și degradantă pentru cei care rămân 
Sciendo

acolo. Ideea era întâlnită încă din proza secolului al XIX-lea, aparținând sămănătorismului. La Slavici, de exemplu, în Comoara, personajul principal este încercat de ispitele orașului, pentru a se întoarce ulterior în spațiul securizant al satului.

În romanul lui Camil Petrescu, „Ultima noapte de dragoste, întâia noapte de război”, autor considerat a fi promotorul citadinismului în literatura română, în opinia teoreticianului modernismului, E. Lovinescu, după prima parte, îndelung analizată și folosită drept exemplu pentru sublinierea influențelor proustiene, gidiene ori stendhaliene, ni se pare relevantă partea secundă. Și nu din perspectiva lui Lovinescu, pentru care această cartea a doua reprezintă „viziunea realistă a unui război fără patriotism și ideologie patriotică” ori despre ,psihologia profesională a războiului” (Pompiliu Constantinescu) sau ,literatura de război, aceea a adevărului” (Perpessicius ), ci despre modul în care spațiul rural este cartografiat de Camil Petrescu. Acest aspect scoate la iveală faptul că autorul modern folosește imaginea satului, zona rurală descrisă putând fi refăcută, chiar dacă unele localități și-au modificat numele din 1930. Tot o încercare de cartografiere face Camil Petrescu în următorul pasaj din roman: „Priveliștea de aci, din turnul Măgurei, e ca de tablou mural, mare cât un județ. Un triunghi cu baza la noi, largă de șapte-opt kilometri, înalt de vreo douăzeci, pare un parc mărginit net de dealuri. Un parc care imita în realitate o hartă: cu satele așa, în forma desenată, de pe hartă, nu cum sunt când te găsești în ele, cu cale ferată, cu șosele ca liniile, fântâni, grădini, biserici. O hartă mărită la scara naturalului și mai viu colorată în verde, alb, negru, roșu, e acum Țara Bârsei, dinaintea noastră. Satul Tohanul Vechi arde pe stinse. Arde încă un sat, departe, mai la dreapta, cu fabrici parcă”. Imaginea panoramică coincide cu o ,lectură de panoramare” (distance reading), menită să creeze la nivel vizual localizarea satelor prin care 
Sciendo

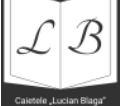

armatele trecuseră sau unde se dăduseră lupte. Redăm o hartă ce urmărește satele despre care vorbește naratorul:

Deși considerat autor tributar citadinismului, prin inserarea în romane a imaginii unor spații urbane, care funcționează ca fundal, constatăm că există multe alte cadre care descriu elemente ale spaţiului rural. De exemplu, un astfel de spațiu este „popota” descrisă astfel: „,e într-o odaie mică, sătească, mai sus decât toate satele românești din munte. E abia mai mare ca o colibă, văruită în alb, cu două paturi înguste la perete, acoperite cu velințe vechi, și care acum ne slujesc și drept scaune de masă. O lampă de «gaz» dă o lumina gălbuie, aproape la fel de leșinată ca a vinului, din paharele mari de apă, de dinainte. Masa e, firește, de brad, ca la cârciumile de drum mare și acoperită cu pânză țărănească”. Spațiul rural își schimbă destinația, în vreme de război, iar ochiul naratorului personaj observă acest lucru. Din aceeași categorie a situării în spațiu și pulverizarea limitelor fac parte și astfel de afirmații: „Lungit pe spate, la şase sute de metri în văzduh, deasupra țării, cu conștiința și cu faţa la cer, sunt parcă într-un punct de pe traiectoria unui proiectil în spațiul interplanetar". Spațiul rural este descris ca un conglomerat, ținând cont de faptul că în regiunea respectivă existau, pe lângă români, comunități de unguri și țigani. Raportarea la etnia romă denotă prejudecățile existente în epocă și nu numai: „Au venit femei, românce de- ale noastre,

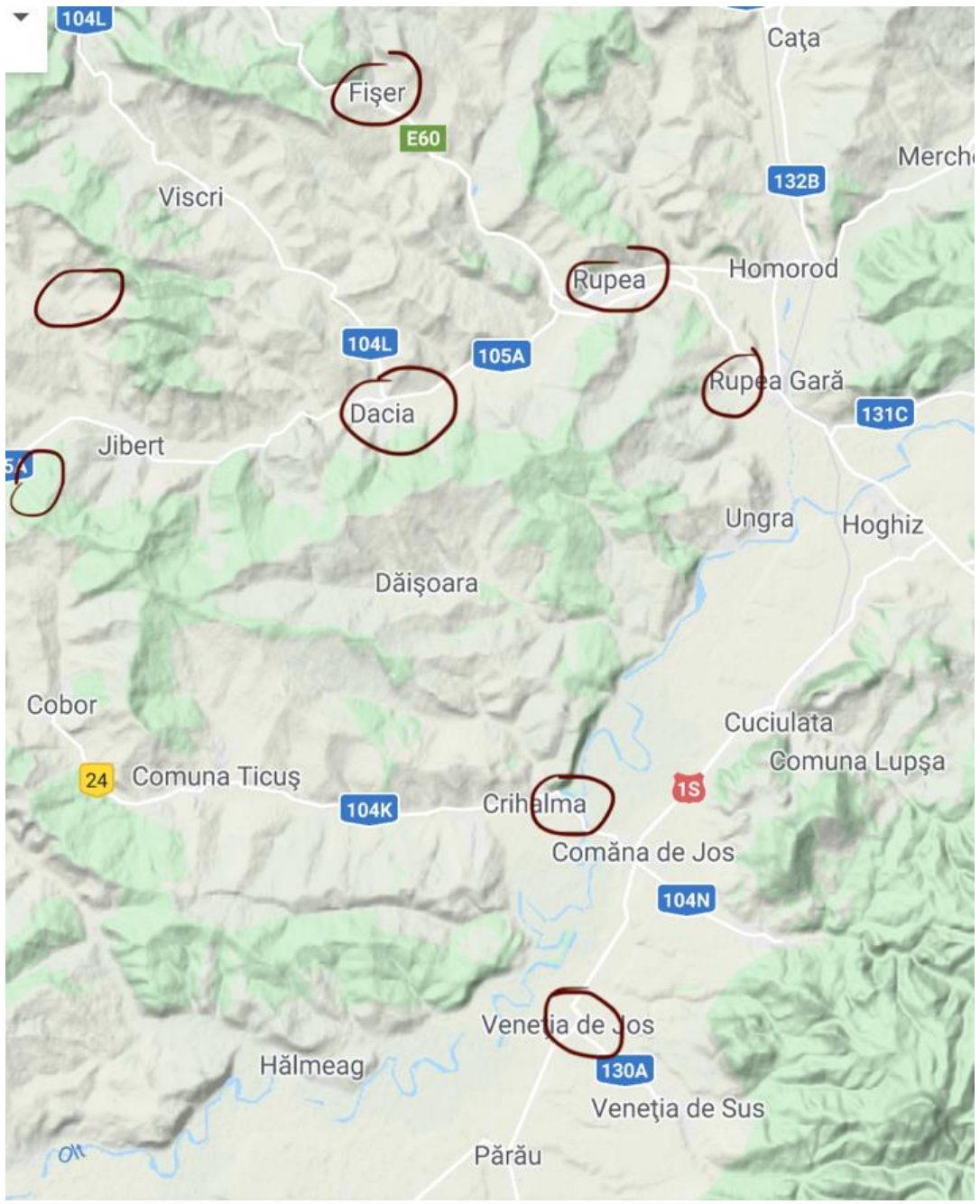




\section{Sciendo}

să se plânga bocind ca de îndată ce satul a fost părăsit de unguri, casele au fost jefuite de țiganii care locuiesc la margine. Vreo două bătrâne mă întovărășesc până acolo, ca să fac o percheziție severă. A plouat repede, apa s-a scurs, soarele a apărut iar din nori, dar frunzele și iarba au străluciri de rouă. În fața cătunului de bordeie, de cum ne-a vazut venind, a ieșit toată țigănimea, și așteapta înspăimântată să ajungem la ea”.

Specificul satelor săsești este surprins de Camil Petrescu, unele sate numite în oraș Fischer sau Ștena aflăm că și-au schimbat numele în Fișer și Dacia. În harta alăturată observăm distribuţia unor astfel de sate, iar descrierea este elocventă: „De după deal vom vedea dintr-o dată satul cu acoperișurile lui roșii de țiglă, cu biserica săsească, ascuțită, cu un tăiș înfipt în albastrul cerului”.

O altă trăsătură interesantă pe care o remarcăm în scrierea lui Camil Petrescu este raportarea spațiului rural la cel urban, prin asocieri precum acestea: „Dar «am cucerit» satul. Coborâm acum pe ulița principală, largă cât două bulevarde din București, cu plantații îngrădite prin mijloc. Copii ne întâmpina din toate părțile și pe la toate ferestrele apar capete curioase, ascunse de după perdele colorate” sau „E o mișcare de cartier în satul în care intrăm în coloană”. Toponimele Câmpulung, Ținutul Branului, Rucăr, Măgura Branului, Tohanu Vechi, Țara Bârsei, Bucegii, Piatra Craiului, Ialomicioara, Râșnov, Vulcan, Codlea, Țânțar, Veneția, Krihalma, Cohalm, Fischer, Stena, Săsăuș, Vâlcelușa, Nagy Varos, Dragoslavele, Bărcuț ne folosesc la reconstituirea coerentă a unui parcurs, dar mai ales la constatarea faptului că în acest roman spațiul rural folosește pentru descrierea unei experiențe limită a umanităţii, războiul. Întreaga regiune pare a fi constituită din, ,pustiul pe care-l întâlnim, sate dupa sate, alt pod care arde", scrie naratorul personaj. Dacă ar fi să folosim formula lui Marc Brosseau, și romanul lui Camil Petrescu poate fi încadrat în formula unuia dintre „romans-géographes”, prin încercarea inedită de cartografiere a spațiului, preponderent rural, de la începutul secolului al XX-lea. Din acest punct de vedere remarcăm cunoștințele geografice ale autorului, precum și ancorarea în realitate, una din caracteristicile prozei care are afinităţi cu geografia.

Bibliografie:

Brosseau, Marc (1996) Des romans-géographes. Essai. Paris, L’Harmattan. 


\section{Sciendo}

Bachelard, Gaston ([1957] 1994). The Poetics of Space: The Classic Look at How We Experience Intimate Places. Boston, Beacon P.

Bahtin, Mihail (Bakhtin, Mikhail) ([1938] 1981). The Dialogic Imagination: Four Essays. Austin.

Chevalier, Michel (1993) Géographie et littérature. Paris, CNRS.

Collot, Michel (2011b) La Pensée-paysage : philosophie, arts, littérature. Arles, Versailles, ENSP.

Dennerlein, Katrin (2009) Narratologie des Raumes. Berlin, de Gruyter.

Doležel, Lubomir (1998) Heterocosmica.Fiction and Possible Worlds. Baltimore, Johns Hopkins U.P.

Fauconnier, Gilles (1997) Mapping in Thought and Language. Cambridge, Cambridge UP.

Frank, Joseph ([1945] 1991) “Spatial Form in Modern Literature.” J. Frank. The Idea of Spatial Form. New Brunswick, Rutgers UP.

Frank, Lanot (2013) « La ville et la littérature » in Thierry Paquot, Michel Lussault (dir.), Dictionnaire de la géographie et de l'espace des sociétés, Paris, Editions Belin

Genette, Gerard (1969) « La littérature et l'espace ». Figures II. Paris, Seuil.

Lotman, Yuri (1999) La Sémiosphère. Limoges, Presses Universitaires de Limoges.

Moretti, Franco (1998). Atlas of the European Novel, 1800-1900. London, Verso.

Page, Ruth (2011). Stories and Social Media: Identities and Interaction. London, Routledge. Ryan, Marie-Laure (2003b). "Cognitive Maps and the Construction of Narrative Space.” D. Herman (ed.). Narrative Theory and the Cognitive Sciences. Stanford: CLSI.

Tally, R.T. (2016) Ecocriticism and Geocriticism. Overlapping Territories in Environmental and Spatial Literary Stdudies. Basingstoke, Palgrave Macmillan.

Tuan, Yi-Fu (1977) Space and Place: The Perspective ofExperience. Minneapolis, UMP. Westphal, Bertrand (2011). Geocriticism. Real and Fictional Spaces. New York, Palgrave Macmillan.

Werth, Paul (1999). Text Worlds: Representing Conceptual Space in Discourse. London, Longman.

Zoran, Gabriel (1984). “Towards a Theory of Space in Fiction.” Poetics Today 5, 309-35.

\section{Romanian Studies:}




\section{CAIETELE "LUCIAN BLAGA" ( LUCIAN BLAGA” YEARBOOK)}

sciendo

Cristea, Valeriu (1979) Spaţiul în literatură, Editura Cartea Românească, București

Macarie, Gheorghe (1980) Geografie literară, Editura Albatros, Bucureşti

Pârvulescu, Ioana (2002) Întoarcere în Bucureştiul interbelic, Editura Humanitas, Bucureşti

Răsuceanu, Andreea (2013) Bucureştiul lui Mircea Eliade. Elemente de geografie literară, Editura Humanitas, Bucureşti

Ungureanu, Cornel (2003) Geografia literaturii române, azi, (vol.I), Editura Paralela 45, Piteşti. 